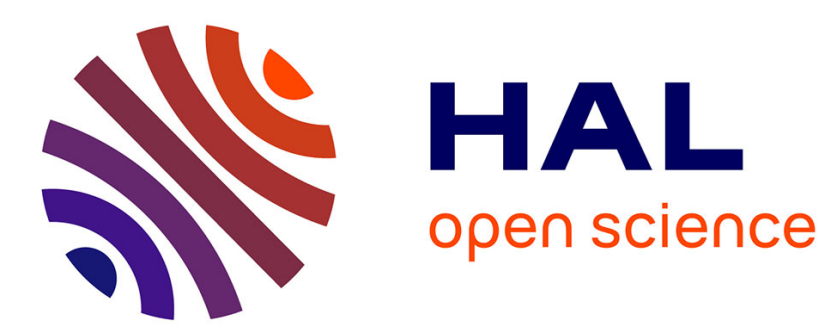

\title{
Allocation constraints in stratification
}

Marcin Kozak, Pawel Jankowski

\section{To cite this version:}

Marcin Kozak, Pawel Jankowski. Allocation constraints in stratification. Communications in Statistics - Simulation and Computation, 2008, 37 (09), pp.1763-1775. 10.1080/03610910802278842 . hal00514328

\section{HAL Id: hal-00514328 \\ https://hal.science/hal-00514328}

Submitted on 2 Sep 2010

HAL is a multi-disciplinary open access archive for the deposit and dissemination of scientific research documents, whether they are published or not. The documents may come from teaching and research institutions in France or abroad, or from public or private research centers.
L'archive ouverte pluridisciplinaire HAL, est destinée au dépôt et à la diffusion de documents scientifiques de niveau recherche, publiés ou non, émanant des établissements d'enseignement et de recherche français ou étrangers, des laboratoires publics ou privés. 


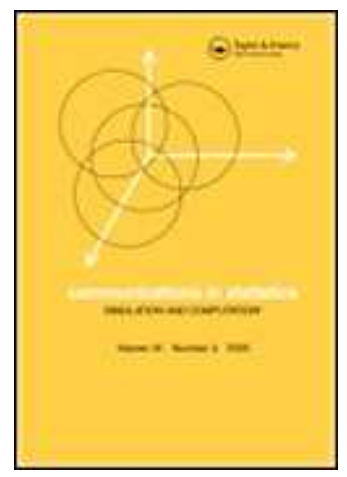

\section{Allocation constraints in stratification}

\begin{tabular}{|c|c|}
\hline Journal: & Communications in Statistics - Simulation and Computation \\
\hline Manuscript ID: & LSSP-2007-0207.R2 \\
\hline Manuscript Type: & Original Paper \\
\hline $\begin{array}{r}\text { Date Submitted by the } \\
\text { Author: }\end{array}$ & 13-Jun-2008 \\
\hline Complete List of Authors: & $\begin{array}{l}\text { Kozak, Marcin; Warsaw University of Life Sciences, Experimental } \\
\text { Design and Bioinformatics } \\
\text { Jankowski, Paweł; Warsaw University of Life Sciences, Biometry }\end{array}$ \\
\hline Keywords: & constraints, optimization, optimum stratification, sample allocation \\
\hline Abstract: & $\begin{array}{l}\text { When a finite population is to be stratified, one of constraints in } \\
\text { stratification is that sample sizes from strata may not be greater } \\
\text { than the corresponding strata sizes and may not be smaller than } \\
\text { two. There are several ways of treating this allocation constraint, } \\
\text { each providing an alternative approach to stratification. In the } \\
\text { paper it is shown that a choice of the approach has a bearing on } \\
\text { stratification efficiency. Unfortunately, no particular approach out of } \\
\text { the four compared is shown to be the most efficient for each } \\
\text { population studied. In addition, the approaches are applied to } \\
\text { stratify a real population. }\end{array}$ \\
\hline
\end{tabular}

\section{$\diamond$ ScholaroNE" \\ Manuscript Central}


1

2

3

4

5

6

7

8

9

10

11

12

13

14

15

16

17

18

19

20

21

22

23

24

25

26

27

28

29

30

31

32

33

34

35

36

37

38

39

40

41

42

43

44

45

46

47

48

49

50

51

52

53

54

55

56

57

58

59

60

\section{Allocation constraints in stratification}

Marcin Kozak ${ }^{1 *}$, Paweł Jankowski ${ }^{2}$

${ }^{1}$ Department of Experimental Design and Bioinformatics, Warsaw University of Life

Sciences, Nowoursynowska 159, 02-787, Warsaw, Poland,

${ }^{2}$ Department of Biometry, Warsaw University of Life Sciences, Nowoursynowska 159,

02-787, Warsaw, Poland,

*Corresponding author, Department of Experimental Design and Bioinformatics,

Warsaw University of Life Sciences

Nowoursynowska 159, 02-787, Warsaw, Poland, e-mail:

m.kozak@omega.sggw.waw.pl

Running head: Allocation constraints in stratification 


\title{
Allocation constraints in stratification
}

\begin{abstract}
When a finite population is to be stratified, one of constraints in stratification is that sample sizes from strata may not be greater than the corresponding strata sizes and may not be smaller than two. There are several ways of treating this allocation constraint, each providing an alternative approach to stratification. In the paper it is shown that a choice of the approach has a bearing on stratification efficiency. Unfortunately, no particular approach out of the four compared is shown to be the most efficient for each population studied. In addition, the approaches are applied to stratify a real population. Keywords: constraints, optimization, optimum stratification, sample allocation Mathematics Subject Classification: Primary 62D05, Secondary 62P20, 62P25.
\end{abstract}

\section{Introduction}

In this paper we consider an optimization approach to stratification, which has been recently proved to be superior to approximate stratification procedures (see Kozak and Verma (2006) and the citations therein). Suppose we aim to stratify a finite population $U$ based on an auxiliary (stratification) variable $X$. Let the aim of stratification be minimizing the variance of an estimator of the population total of a study variable $Y$ subject to fixed sample size $n$. At the design stage of a survey it is usually assumed that a survey variable $(Y)$ and stratification variable $(X)$ be the same and that there be no non-responses. This is, of course, never the case in practice, yet such an approach is common and is not thought of as controversial. Furthermore, let us consider the common practical situation in which the survey and stratification variables are 
positively skewed; then, the most efficient approach is to construct a so-called take-all stratum, from which all the elements are taken to the sample (e.g., Hidiroglou, 1986; Lavallée and Hidiroglou, 1988).

The objective function to be minimized in the problem in question is the variance $\operatorname{Var}\left(\hat{t}_{X}\right)$ of an estimator $\hat{t}_{X}$ of the population total of $X$. Assuming that the $L$ th stratum is the take-all one, the variance, under the take-all stratum approach, takes the form

$$
\begin{aligned}
& \operatorname{Var}\left(\hat{t}_{X}\right)=\sum_{h=1}^{L-1} S_{h}^{2} W_{h}^{2}\left(\frac{1}{n_{h}}-\frac{1}{N_{h}}\right) \\
& \hat{t}_{X}=\sum_{h=1}^{L} \frac{N_{h}}{n_{h}} \sum_{k=1}^{n_{h}} X_{h k} ; t_{X}=\sum_{h=1}^{L} \sum_{k=1}^{N_{h}} X_{h k} ; W_{h}=N_{h} / \sum_{h=1}^{L} N_{h} ; \\
& S_{h}^{2}=\frac{1}{N_{h}-1} \sum_{k=1}^{N_{h}}\left(X_{h k}-\bar{X}_{h}\right)^{2} \text { for } h=1, \ldots, L-1 ; \bar{X}_{h}=\frac{1}{N_{h}} \sum_{k=1}^{N_{h}} X_{h k}
\end{aligned}
$$

where $\hat{t}_{X}$ is the unbiased estimator of the population total $t_{X}$ of $X ; S_{h}^{2}$ is the population variance of the variable $X$ restricted to the $h$ th stratum; $n_{h}$ is the sample size from the $h$ th stratum of size $N_{h} ; X_{h k}$ is the value of $X$ for the $k$ th population element of the $h$ th stratum; and $\bar{X}_{h}$ is the population mean of $X$ restricted to the stratum $h$. In equation (1), we have considered the most classical unbiased estimation of the population total under stratified sampling; see, e.g., Särndal et al. (1992).

A vector of stratification points, say $\mathbf{a}=\left(a_{1}, \ldots, a_{L-1}\right)^{T}$, which explicitly defines the subdivision of the population $U$ into strata, is a vector of parameters to be searched for (e.g., Lednicki and Wieczorkowski, 2003). It is to be noted that the variance (1) does not directly involve the parameters sought. An objective function $f(\mathbf{a})$ can be written in a general form as

$$
f(\mathbf{a})=\operatorname{Var}\left(\hat{t}_{X}\right)
$$


where $\operatorname{Var}\left(\hat{t}_{X}\right)$ is given in equation (1). The constraints for the function (2) are as follows:

$$
\begin{aligned}
& 2 \leq n_{h} \leq N_{h}, h=1, \ldots, L-1 \\
& N_{h} \geq 2 ; h=1, \ldots, L \\
& N_{L}+\sum_{h=1}^{L-1} n_{h}=n
\end{aligned}
$$

Fulfilling the constraints (3) and (4) is required to ensure that the variance (1) can be evaluated. (Note that the constraint $N_{L} \geq 2$ is not required here, but it is reasonable to use it in order to obtain a take-all stratum comprising at least two elements.) Sample sizes $n_{h}$ from strata are usually determined through the Neyman optimum sample allocation, which aims at minimizing the variance (1); after adjusting the formula for the take-all stratum approach, the sample sizes are given by

$$
n_{h}=\left(n-N_{L}\right) \frac{W_{h} S_{h}}{\sum_{h=1}^{L-1} W_{h} S_{h}}, h=1, \ldots, L-1 ; n_{L}=N_{L}
$$

There are two possible ways of treating the constraints (3): (i) one does not accept the solution in which any $n_{h}$ provided by the formula (6) does not fulfil the constraints (3), and changes the stratification points (such an approach was applied, for instance, by Lednicki and Wieczorkowski (2003)); and (ii) one does not accept the allocation and searches for the optimum allocation using numerical optimization. The first approach is obviously easier to implement and provides less time-consuming computation. However, intuition makes us suppose that this approach may give rise to rejecting solutions that either are optimal or may be connections between stratification points considered in a particular step and the optimum points (or a path leading to the optimum points). 
1

3

4

5

6

7

8

9

10

11

12

13

14

15

16

17

18

19

20

21

22

23

24

25

26

27

28

29

30

31

32

33

34

35

36

The option (i) of treating the constraints can be applied in two manners. First, one can reject points not fulfilling the constraints (3). Second, one can apply the following procedure to adjust the sample sizes for the constraints: determine $n_{h}$ through the allocation (6) and apply the following formula (for $h=1, \ldots, L-1$ )

$$
n_{h}=2 \text { if } n_{h}<2 ; n_{h}=N_{h} \text { if } n_{h}>N_{h}
$$

This procedure makes us accept solutions that would be rejected by the first manner, in which way a set of possible solutions is widened.

In this paper we compare the following approaches to treating the allocation constraints in stratification:

(A) Approach based on not accepting a solution (stratification) in which any $n_{h}$ provided by the formula (6) does not fulfil the constraints (3).

(B) Approach based on applying the allocation (6) with the adjustment (7).

(C) Approach based on applying numerical optimization to allocate the sample: if $n_{h}$ 's provided by the formula (6) do not fulfil the constraints (3), solve the following problem to find the allocation. Given a vector of stratification points $\mathbf{a}$, find such $n_{h}$ 's, $h=1, \ldots, L-1$, that minimize the objective function (1), i.e., $f\left(n_{1}, \ldots, n_{L-1}\right)=\operatorname{Var}\left(\hat{t}_{X}\right)$, under the constraints (3) and (5).

Kozak (2004b) showed that results of stratification determined by numerical optimization depend on stratification points that are used as initial parameters in the optimization. Therefore, we will consider an additional approach as follows:

(D) Approach based on applying approach $\mathrm{C}$ with strata boundaries provided by approach B taken as initial parameters in optimization. 
Hence, a question to answer is, does the choice of an approach of treating the allocation constraints in stratification have an influence on stratification efficiency? The aim of the paper is to answer this question through a simulation study.

\section{Design of experiment}

The following aspects of a population and a stratification variable were considered in the experiment: (i) population size $N$, viz., $N=\{1000,2000,5000,10000,15000\}$; (ii) number $L$ of strata to be constructed, viz., $L=\{3,5,7,9\}$; (c) sample fraction $f=n / N$ ( $n$ being the assumed sample size), viz., $f=\{0.1,0.2\}$; and (d) parameter $\sigma$ of the distribution of the stratification variable (see below), viz., $\sigma=\{0.4,0.6,0.8\}$. For the sake of convenience, below the population quantities $N, L, f$, and $\sigma$ will be referred to as factors.

Stratification variables were generated based on the following formula:

$$
X=[\exp (Z)]
$$

where $Z$ is the realization of an $N\left(10, \sigma^{2}\right)$ variable (a normal random variable with mean 10 and standard deviation $\sigma$ ) and the function $[\cdot]$ stands for rounding to integers (to simulate the most often practical situation). As a result of such generation, the variables were positively skewed; the greater the $\sigma$ value, the greater the skewness was.

For each combination of $N \times L \times f \times \sigma, 100$ independent populations (stratification variables) were generated; thus there were 12000 populations altogether. For an $i$ th population, the four stratification approaches of study were applied and the coefficient of variation $c v_{k i}\left(\hat{t}_{X}^{i}\right)(k$ referring to the $k$ th approach to stratification, $k=A, B, C, D)$ of the estimator $\hat{t}_{X}^{i}$ was evaluated using the formula 
1

2

3

4

5

6

7

8

9

10

11

12

13

$$
c v_{k i}\left(\hat{t}_{X}^{i}\right)=\left(t_{X}^{i}\right)^{-1} \sqrt{\operatorname{Var}_{k}\left(\hat{t}_{X}^{i}\right)}
$$

where $\operatorname{Var}_{k}\left(\hat{t}_{X}^{i}\right)$ is the variance (1) of the estimator $\hat{t}_{X}^{i}$ under the $k$ th approach to stratification, and $t_{X}^{i}$ is the total of $X$ in the $i$ th population.

As Lednicki and Wieczorkowski (2003) did, to perform stratification we have applied optim function, which implements the algorithm of the simplex method of Nelder and Mead (1965), available in R language and environment (R Development Core Team 2007). Following Kozak's (2004a) results on efficiency of approximate stratification points used as initial parameters in optimization, stratification points determined by Mahalanobis's (1952) procedure were taken as the initial vector of parameters in optimization. However, because this procedure does not take account of the take-all stratum approach, the point defining the last stratum was changed in such a way that this stratum comprised five population elements with the largest values of the stratification variable. (Note that the take-all stratum contained five elements at the initial stage of stratification, but later the number of its elements was not limited to five.) Whenever these stratification points did not fulfil the constraints (3) and/or (4), we used the points provided by (i) the Ekman (1959) procedure; (ii) then, whenever Ekman's points failed, the Dalenius and Hodges (1959) procedure were applied; and finally, (iii) whenever Dalenius and Hodges' points failed, we used the Gunning and Horgan (2004) procedure. Each such procedure was applied with the above-mentioned adjustment for the take-all stratum approach. However, whenever all these procedures failed to fulfil the constraints (3), the initial strata were constructed based on the following procedure. First, the five-element take-all stratum had been constructed, and then the remaining part of the population was subdivided into $L-1$ strata of equal sizes (or nearly equal, if $(N-5) /(L-1)$ was not an integer). 
In the approaches $\mathrm{C}$ and $\mathrm{D}, \mathrm{R}$ 's function optim was applied to determine the optimum sample allocation; as the initial parameters (sample sizes from strata) in the optimization, the $(L-1)$-vector of twos was taken.

All the computation was performed in R (R Development Core Team, 2007) using self-implemented functions, which can be obtained from the corresponding author upon request.

\section{Results}

Results of the simulation study are presented in Tables 1-5, for $N=1000,2000,5000$, 10000 and 15000, respectively. For a particular population we calculated ranks for the values of the coefficient of variation (cv), given by Eq. (8), of the estimator obtained under the four approaches. Then we determined the number of times in which (i) a particular approach was the best (cv obtained under approach A, C, or D had rank 1; cv obtained under approach B had rank 1.5 provided that $\mathrm{cv}$ obtained under approach D had rank 1.5, too); (ii) a particular approach was the worst (cv obtained under approach $\mathrm{A}$ or $\mathrm{C}$ had rank 4; cv obtained under approach $\mathrm{B}$ had rank 3.5 , provided that $\mathrm{cv}$ obtained under approach D had rank 3.5, or rank 4; cv obtained under approach D had rank 3.5 provided that cv obtained under approach B had rank 3.5, too). Through this analysis of ranks approach B was recognized as the best in a situation when approach D had not improved its results and approaches A and C had been worse (we would not recognize approach $\mathrm{D}$ as the best then, since its application did not provide any gain in efficiency in comparison to its initial parameters that had been provided by approach B). On the other hand, approach D was recognized as the worst when it had not improved 
1

3

4

5

6

7

8

9

10

11

12

13

14

15

16

17

18

19

20

21

22

23

24

25

26

27

28

29

30

31

32

33

34

35

36

the results of approach $\mathrm{B}$, of which the results of approaches $\mathrm{A}$ and $\mathrm{C}$ had been better (in such a situation approach B was also recognized as the worst).

[Table 1]

[Table 2]

[Table 3]

[Table 4]

[Table 5]

In addition, Table 6 contains mean ranks determined for the approaches under a particular level of the population quantities studied; from this table it follows that in general approach $\mathrm{D}$ appears to be the best (in the sense that it provides the most efficient stratification points); approaches A, B and C seem to provide similar results (inferior to those of approach D), even though a slight tendency of approach $\mathrm{C}$ to be better than approaches A and B has been detected. Such a result has been obtained for all the levels of the factors studied except for $L=3$, in which case all the approaches provided similar mean ranks though approach $\mathrm{D}$ appeared to be slightly better than the other approaches. For all the other factor levels, cv obtained under approach D had the smallest mean rank. Usually cv obtained under approach $\mathrm{C}$ had a little smaller mean rank than cvs obtained under approaches $\mathrm{A}$ and $\mathrm{B}$, but for some combinations cvs obtained under approaches A, B and C had similar mean ranks. Differences between the values of cv obtained by different approaches were sometimes meaningful (e.g., it sometimes happened that $c v_{\text {worst }}>1.5 c v_{\text {best }}$, the first $\mathrm{cv}$ referring to the worst and the second to the best approach). 
[Table 6]

Several interesting situations occurred. Under $\sigma=0.4$ and 0.6 , the larger $L$, the more often approach $\mathrm{D}$ was the best. However, this situation did not occur under $\sigma=0.8$. In general, under $L=5,7$ and 9, approaches A and $\mathrm{B}$, and sometimes $\mathrm{C}$, were quite often the worst. In general, approach B was seldom the best; neither was approach C, although under $\sigma=0.8, f=0.2$, and $L=7$ and 9 it was usually the best. The hypothesis that approach C and/or D may always be the best, which was mentioned in Introduction, has not been proven correct by our experiment. Nonetheless, in most situations approach D often appeared the best; in addition, it seldom was the worst. That approach D was usually better than approach $\mathrm{C}$ is easy to explain—it resulted from more efficient initial strata points used in the former than those used in the latter. Nonetheless, let us recall the combinations $\sigma=0.8, f=0.2$, and $L=7$ and 9 , in which, without any reasonable and explicable reason, approach $\mathrm{D}$ was usually worse than approach $\mathrm{C}$.

Approach A has one important drawback that must be mentioned here. There were many populations, especially under high $N, \sigma$, and $f$ values, for which the optimization was unable to perform this stratification based on all the initial values mentioned, for which reason this approach failed to stratify such populations. This situation did not occur for any other approach.

We have not studied the approach in which the results of approach A would be taken as initial parameters to perform optimization in approach $\mathrm{C}$. The main reason was that such an approach would fail in a situation in which approach A did not succeed to provide stratification points fulfilling the constraints (3) and (4).

Based on the results obtained we are not able to choose the best approach explicitly. In practice the best way is to apply all the approaches (even with points provided by the 
approach A taken as initial parameters if only they are feasible) and to choose the best one. However, if for any reason it is unlikely to be done, approach D should be chosen, as the best and the least risky in our experiment. Of course, a simulation study as it is, it does consider a somewhat limited range of possible populations and stratification approaches (e.g., a population size, variability in a stratification variable, number of strata to be constructed, and the like). It is possible that considering other population and stratification attributes, we could obtain different results. Nonetheless, this would not change our conclusions that we cannot point out any particular approach as the best one, and that the choice of an approach does count even though still no explicit recommendation can be given.

The most possible reason why approaches $\mathrm{C}$ and $\mathrm{D}$ were not the best for all the populations is that Nelder and Mead's optimization might lead to the local minimum of a function optimized. Moreover, initial stratification points have a bearing on the optimization results (Kozak, 2004b). We have applied several approximate stratification procedures to provide initial stratification points, but there is no certainty that those stratification points are really the best ones. Further efforts should be focused on determining a procedure that would provide more efficient stratification than Nelder and Mead's optimization approach does. Kozak's (2004a) random search algorithm is a very promising one, as claimed by Baillargeon and Rivest (2007), but we need to remember that as a global optimization method this procedure provides random results. Hence the best option is to apply it several times (maybe with various starting points) to ensure that the results obtained are indeed globally and not locally optimum. Worth noting is that Baillargeon and Rivest (2007) implemented a non-random version of the algorithm, which is of course free of the problem of random results. 


\section{Example}

Here we apply the four allocations for a real data set SHS available in the package stratification (Baillargeon and Rivest, 2007) of R (R Development Core Team, 2007). The set contains data for 16057 units from the 2001 Survey of Household Spending (SHS) Statistics Canada; for stratification we will use one variable, namely "household income before taxes". The results are given in Table 7.

Apparently approaches A and D were the most and approach C the least efficient for this particular data set. Interestingly, all the approaches provided the same take-all stratum (even though the boundaries for the take-all strata they provided differed, all of them comprised the same eight population units). Note that due to rounding of sample sizes from strata there were some inconsistencies in overall sample sizes as in none of the cases it equalled 1500 (it was either 1499 or 1501), but for so large a sample size these two elements did not make any real difference.

[Table 7]

\section{Conclusion}

This paper aimed to show that the way of treating the constraint (3) does matter. This has been proven indeed: The choice may cause results of stratification under various treating the constraints be very different in terms of the precision of estimation of a parameter studied. Unfortunately, of four such ways considered in this paper, none was ultimately the best. 
1

2

3

4

5

6

7

8

9

10

11

12

13

From the results we have concluded that in practical applications the best way is to apply all the approaches and to choose the best one for the particular population. If this is impossible, approach D should be applied as most often the best and the least risky in our experiment.

\section{References}

Baillargeon, S. and L.P. Rivest (2007). stratification: Stratification of Survey Populations. R package version 1.0.

Dalenius, T. and Hodges, J.L. (1959). Minimum Variance Stratification. Journal of the American Statistical Association 54:88-101.

Ekman, G., (1959), An Approximation Useful in Univariate Stratification. Annals of Mathematical Statistics 30:219-229.

Gunning, P. and Horgan, J.M. (2004). A Simple Algorithm for Stratifying Skewed Populations. Survey Methodology 30:159-166.

Hidiroglou, M. (1986). The Construction of a Self-Representing Stratum of Large Units in Survey Design. The American Statistician 40:27-31.

Kozak, M. (2004a). Optimal Stratification Using Random Search Method in Agricultural Surveys. Statistics in Transition 6 (5):797—806.

Kozak, M. (2004b). Optimal Stratification with the Auxiliary Variable. Wiadomosci Statystyczne (Statistical News) 8:29-34 (in Polish).

Kozak, M. and Verma, M.R. (2006). Geometric Versus Optimization Approach to Stratification: A Comparison of Efficiency. Survey Methodology 32(2):157-163. Lavallée, P. and Hidiroglou, M. (1988). On the Stratification of Skewed Population. Survey Methodology 14:3—43. 
Lednicki, B. and Wieczorkowski, R. (2003). Optimal Stratification and Sample Allocation between Subpopulations and Strata. Statistics in Transition 6:287-306.

Mahalanobis, P.C. (1952). Some Aspects of the Design of Sample Surveys. Sankhya $12: 1-7$.

Nelder, J.A. and Mead, R. (1965). A Simplex Method for Function Minimization. Computer Journal 7:308-313.

R Development Core Team (2007). R: A language and environment for statistical computing. R Foundation for Statistical Computing, Vienna, Austria; URL http://www.R-project.org.

Särndal, C.E., Swensson, B. and Wretman, J. (1992). Model Assisted Survey Sampling. New York: Springer-Verlag. 
Table 1. Summary of rank-ordering of efficiency of stratification approaches A, B, C, and $\mathrm{D}$, for $N=1000$ and various combinations of $\sigma, f, L$.

\begin{tabular}{|c|c|c|c|c|c|c|c|c|c|c|c|}
\hline$\sigma$ & $f$ & $L$ & $\begin{array}{l}\mathrm{A}^{\mathrm{a}} \\
\text { best }\end{array}$ & $\begin{array}{l}\mathrm{A}^{\mathrm{a}} \\
\text { worst }\end{array}$ & $\begin{array}{l}\mathrm{A}^{\mathrm{b}} \\
\text { failed }\end{array}$ & $\begin{array}{l}\mathrm{B}^{\mathrm{c}} \\
\text { best }\end{array}$ & $\begin{array}{l}\mathrm{B}^{\mathrm{d}} \\
\text { worst }\end{array}$ & $\begin{array}{l}\mathrm{C}^{\mathrm{a}} \\
\text { best }\end{array}$ & $\begin{array}{l}\mathrm{C}^{\mathrm{a}} \\
\text { worst }\end{array}$ & $\begin{array}{l}\mathrm{D}^{\mathrm{e}} \\
\text { best }\end{array}$ & $\begin{array}{l}D^{f} \\
\text { worst }\end{array}$ \\
\hline 0.4 & 0.1 & 3 & 0 & 0 & 0 & 0 & 0 & 0 & 0 & 7 & 0 \\
\hline 0.4 & 0.1 & 5 & 12 & 17 & 0 & 5 & 22 & 13 & 38 & 25 & 3 \\
\hline 0.4 & 0.1 & 7 & 20 & 28 & 0 & 9 & 24 & 20 & 42 & 48 & 3 \\
\hline 0.4 & 0.1 & 9 & 22 & 19 & 0 & 1 & 24 & 8 & 56 & 69 & 0 \\
\hline 0.4 & 0.2 & 3 & 2 & 3 & 0 & 0 & 0 & 0 & 0 & 7 & 0 \\
\hline 0.4 & 0.2 & 5 & 18 & 33 & 0 & 3 & 6 & 2 & 6 & 46 & 0 \\
\hline 0.4 & 0.2 & 7 & 17 & 39 & 0 & 2 & 20 & 11 & 24 & 66 & 0 \\
\hline 0.4 & 0.2 & 9 & 18 & 43 & 3 & 1 & 31 & 12 & 24 & 69 & 0 \\
\hline 0.6 & 0.1 & 3 & 1 & 0 & 0 & 0 & 0 & 0 & 1 & 12 & 0 \\
\hline 0.6 & 0.1 & 5 & 18 & 21 & 1 & 12 & 16 & 17 & 43 & 33 & 4 \\
\hline 0.6 & 0.1 & 7 & 19 & 21 & 1 & 6 & 24 & 19 & 50 & 54 & 3 \\
\hline 0.6 & 0.1 & 9 & 14 & 16 & 0 & 2 & 15 & 8 & 68 & 76 & 0 \\
\hline 0.6 & 0.2 & 3 & 2 & 6 & 0 & 1 & 0 & 0 & 0 & 9 & 0 \\
\hline 0.6 & 0.2 & 5 & 16 & 62 & 0 & 2 & 4 & 0 & 4 & 72 & 0 \\
\hline 0.6 & 0.2 & 7 & 17 & 39 & 0 & 0 & 30 & 14 & 22 & 68 & 1 \\
\hline 0.6 & 0.2 & 9 & 28 & 37 & 2 & 0 & 31 & 23 & 32 & 49 & 0 \\
\hline 0.8 & 0.1 & 3 & 0 & 2 & 0 & 0 & 0 & 1 & 0 & 18 & 0 \\
\hline 0.8 & 0.1 & 5 & 12 & 32 & 0 & 10 & 28 & 29 & 25 & 40 & 6 \\
\hline 0.8 & 0.1 & 7 & 16 & 21 & 0 & 3 & 16 & 13 & 59 & 66 & 2 \\
\hline 0.8 & 0.1 & 9 & 5 & 27 & 0 & 3 & 11 & 8 & 62 & 84 & 0 \\
\hline 0.8 & 0.2 & 3 & 2 & 9 & 0 & 0 & 0 & 0 & 0 & 6 & 0 \\
\hline 0.8 & 0.2 & 5 & 9 & 58 & 1 & 3 & 3 & 2 & 9 & 73 & 1 \\
\hline 0.8 & 0.2 & 7 & 23 & 34 & 7 & 0 & 39 & 19 & 22 & 57 & 1 \\
\hline 0.8 & 0.2 & 9 & 13 & 66 & 2 & 1 & 22 & 63 & 12 & 23 & 0 \\
\hline
\end{tabular}

a "A best", "C best", "A worst", and "C worst" indicate number of times in which a particular approach (A or C) had rank 1 (best) or rank 4 (worst); " "A failed" indicates number of time in which numerical problems occurred under approach $\mathrm{A}$, so the solution was not be found; ${ }^{\mathrm{c}}$ "B best" indicates number of times in which this approach had rank 1.5 provided that approach D had rank 1.5, too; "B worst" indicates 
number of times in which this approach had rank 4 or 3.5 provided that approach $\mathrm{D}$ also had rank $3.5 ;{ }^{\mathrm{e}}$ " $\mathrm{D}$ best" indicates number of times in which approach $\mathrm{D}$ had rank $1 ;$; "D worst" indicates number of times in which this approach had rank 3.5 provided that approach B had rank 1, too. 
Table 2. Summary of rank-ordering of efficiency of stratification approaches A, B, C, and $\mathrm{D}$, for $N=2000$ and various combinations of $\sigma, f, L$.

\begin{tabular}{|c|c|c|c|c|c|c|c|c|c|c|c|}
\hline$\sigma$ & $f$ & $L$ & $\begin{array}{l}\mathrm{A}^{\mathrm{a}} \\
\text { best }\end{array}$ & $\begin{array}{l}\mathrm{A}^{\mathrm{a}} \\
\text { worst }\end{array}$ & $\begin{array}{l}\mathrm{A}^{\mathrm{b}} \\
\text { failed }\end{array}$ & $\begin{array}{l}\mathrm{B}^{\mathrm{c}} \\
\text { best }\end{array}$ & $\begin{array}{l}\mathrm{B}^{\mathrm{d}} \\
\text { worst }\end{array}$ & $\begin{array}{l}\mathrm{C}^{\mathrm{a}} \\
\text { best }\end{array}$ & $\begin{array}{l}\mathrm{C}^{\mathrm{a}} \\
\text { worst }\end{array}$ & $\begin{array}{l}\mathrm{D}^{\mathrm{e}} \\
\text { best }\end{array}$ & $\begin{array}{l}D^{f} \\
\text { worst }\end{array}$ \\
\hline 0.4 & 0.1 & 3 & 0 & 0 & 0 & 0 & 0 & 0 & 0 & 4 & 0 \\
\hline 0.4 & 0.1 & 5 & 19 & 43 & 0 & 1 & 6 & 0 & 2 & 37 & 1 \\
\hline 0.4 & 0.1 & 7 & 25 & 35 & 0 & 1 & 31 & 10 & 15 & 62 & 0 \\
\hline 0.4 & 0.1 & 9 & 35 & 29 & 0 & 0 & 42 & 11 & 26 & 54 & 0 \\
\hline 0.4 & 0.2 & 3 & 2 & 4 & 0 & 0 & 0 & 0 & 0 & 3 & 0 \\
\hline 0.4 & 0.2 & 5 & 13 & 42 & 0 & 0 & 4 & 0 & 2 & 62 & 0 \\
\hline 0.4 & 0.2 & 7 & 22 & 47 & 0 & 0 & 17 & 6 & 14 & 72 & 0 \\
\hline 0.4 & 0.2 & 9 & 16 & 53 & 0 & 0 & 19 & 4 & 20 & 80 & 0 \\
\hline 0.6 & 0.1 & 3 & 0 & 1 & 0 & 0 & 0 & 0 & 0 & 5 & 0 \\
\hline 0.6 & 0.1 & 5 & 18 & 57 & 0 & 3 & 10 & 1 & 2 & 58 & 0 \\
\hline 0.6 & 0.1 & 7 & 31 & 20 & 0 & 0 & 37 & 8 & 33 & 59 & 0 \\
\hline 0.6 & 0.1 & 9 & 30 & 19 & 1 & 0 & 40 & 14 & 41 & 56 & 0 \\
\hline 0.6 & 0.2 & 3 & 1 & 4 & 0 & 0 & 0 & 0 & 0 & 12 & 0 \\
\hline 0.6 & 0.2 & 5 & 10 & 59 & 0 & 0 & 1 & 1 & 3 & 75 & 0 \\
\hline 0.6 & 0.2 & 7 & 17 & 39 & 0 & 1 & 18 & 1 & 19 & 80 & 1 \\
\hline 0.6 & 0.2 & 9 & 23 & 48 & 1 & 0 & 33 & 28 & 12 & 49 & 0 \\
\hline 0.8 & 0.1 & 3 & 0 & 3 & 0 & 0 & 0 & 0 & 0 & 18 & 0 \\
\hline 0.8 & 0.1 & 5 & 17 & 54 & 0 & 3 & 7 & 3 & 5 & 62 & 0 \\
\hline 0.8 & 0.1 & 7 & 28 & 21 & 0 & 1 & 39 & 20 & 38 & 51 & 1 \\
\hline 0.8 & 0.1 & 9 & 31 & 18 & 0 & 1 & 33 & 17 & 49 & 51 & 1 \\
\hline 0.8 & 0.2 & 3 & 1 & 10 & 0 & 0 & 0 & 0 & 0 & 19 & 0 \\
\hline 0.8 & 0.2 & 5 & 13 & 58 & 4 & 1 & 3 & 2 & 7 & 68 & 1 \\
\hline 0.8 & 0.2 & 7 & 10 & 60 & 7 & 2 & 23 & 45 & 7 & 43 & 1 \\
\hline 0.8 & 0.2 & 9 & 3 & 82 & 46 & 0 & 18 & 85 & 0 & 12 & 0 \\
\hline
\end{tabular}

a "A best", "C best", "A worst", and "C worst" indicate number of times in which a particular approach (A or C) had rank 1 (best) or rank 4 (worst); " "A failed" indicates number of time in which numerical problems occurred under approach $\mathrm{A}$, so the solution was not be found; ${ }^{\mathrm{c}}$ "B best" indicates number of times in which this approach had rank 1.5 provided that approach D had rank 1.5, too; "B worst" indicates 
number of times in which this approach had rank 4 or 3.5 provided that approach $\mathrm{D}$ also had rank $3.5 ;{ }^{\mathrm{e}}$ " $\mathrm{D}$ best" indicates number of times in which approach $\mathrm{D}$ had rank $1 ;$; "D worst" indicates number of times in which this approach had rank 3.5 provided that approach B had rank 1, too. 
Table 3. Summary of rank-ordering of efficiency of stratification approaches A, B, C, and $\mathrm{D}$, for $N=5000$ and various combinations of $\sigma, f, L$.

\begin{tabular}{|c|c|c|c|c|c|c|c|c|c|c|c|}
\hline$\sigma$ & $f$ & $L$ & $\begin{array}{l}\mathrm{A}^{\mathrm{a}} \\
\text { best }\end{array}$ & $\begin{array}{l}\mathrm{A}^{\mathrm{a}} \\
\text { worst }\end{array}$ & $\begin{array}{l}\mathrm{A}^{\mathrm{b}} \\
\text { failed }\end{array}$ & $\begin{array}{l}\mathrm{B}^{\mathrm{c}} \\
\text { best }\end{array}$ & $\begin{array}{l}\mathrm{B}^{\mathrm{d}} \\
\text { worst }\end{array}$ & $\begin{array}{l}\mathrm{C}^{\mathrm{a}} \\
\text { best }\end{array}$ & $\begin{array}{l}\mathrm{C}^{\mathrm{a}} \\
\text { worst }\end{array}$ & $\begin{array}{l}\mathrm{D}^{\mathrm{e}} \\
\text { best }\end{array}$ & $\begin{array}{l}\mathrm{D}^{\mathrm{f}} \\
\text { worst }\end{array}$ \\
\hline 0.4 & 0.1 & 3 & 0 & 0 & 0 & 0 & 0 & 0 & 0 & 7 & 0 \\
\hline 0.4 & 0.1 & 5 & 22 & 35 & 0 & 1 & 3 & 1 & 2 & 41 & 0 \\
\hline 0.4 & 0.1 & 7 & 12 & 60 & 0 & 1 & 10 & 2 & 8 & 85 & 0 \\
\hline 0.4 & 0.1 & 9 & 8 & 57 & 0 & 0 & 20 & 2 & 12 & 90 & 0 \\
\hline 0.4 & 0.2 & 3 & 0 & 0 & 0 & 0 & 0 & 0 & 0 & 8 & 0 \\
\hline 0.4 & 0.2 & 5 & 3 & 39 & 0 & 1 & 0 & 2 & 2 & 66 & 0 \\
\hline 0.4 & 0.2 & 7 & 17 & 48 & 0 & 0 & 15 & 6 & 14 & 76 & 0 \\
\hline 0.4 & 0.2 & 9 & 14 & 49 & 0 & 0 & 18 & 6 & 20 & 80 & 0 \\
\hline 0.6 & 0.1 & 3 & 1 & 1 & 0 & 0 & 0 & 0 & 0 & 11 & 0 \\
\hline 0.6 & 0.1 & 5 & 10 & 41 & 0 & 1 & 8 & 2 & 6 & 65 & 0 \\
\hline 0.6 & 0.1 & 7 & 13 & 47 & 0 & 1 & 20 & 5 & 18 & 81 & 0 \\
\hline 0.6 & 0.1 & 9 & 26 & 32 & 0 & 0 & 26 & 2 & 26 & 72 & 0 \\
\hline 0.6 & 0.2 & 3 & 0 & 0 & 0 & 0 & 0 & 0 & 0 & 22 & 0 \\
\hline 0.6 & 0.2 & 5 & 7 & 47 & 0 & 1 & 3 & 1 & 2 & 73 & 0 \\
\hline 0.6 & 0.2 & 7 & 7 & 42 & 0 & 0 & 25 & 9 & 18 & 84 & 0 \\
\hline 0.6 & 0.2 & 9 & 4 & 86 & 2 & 0 & 6 & 51 & 8 & 45 & 0 \\
\hline 0.8 & 0.1 & 3 & 0 & 6 & 0 & 0 & 0 & 0 & 0 & 11 & 0 \\
\hline 0.8 & 0.1 & 5 & 11 & 44 & 0 & 4 & 8 & 1 & 7 & 69 & 0 \\
\hline 0.8 & 0.1 & 7 & 22 & 61 & 3 & 0 & 12 & 8 & 10 & 69 & 0 \\
\hline 0.8 & 0.1 & 9 & 32 & 17 & 0 & 0 & 37 & 5 & 39 & 63 & 0 \\
\hline 0.8 & 0.2 & 3 & 0 & 5 & 0 & 0 & 0 & 0 & 0 & 18 & 0 \\
\hline 0.8 & 0.2 & 5 & 14 & 35 & 0 & 1 & 3 & 3 & 7 & 40 & 1 \\
\hline 0.8 & 0.2 & 7 & 2 & 76 & 3 & 0 & 23 & 79 & 0 & 19 & 1 \\
\hline 0.8 & 0.2 & 9 & 0 & 100 & 85 & 0 & 0 & 96 & 0 & 4 & 0 \\
\hline
\end{tabular}

a "A best", "C best", "A worst", and "C worst" indicate number of times in which a particular approach (A or C) had rank 1 (best) or rank 4 (worst); " "A failed" indicates number of time in which numerical problems occurred under approach $\mathrm{A}$, so the solution was not be found; ${ }^{c}$ "B best" indicates number of times in which this approach had rank 1.5 provided that approach D had rank 1.5 , too; "B worst" indicates 
number of times in which this approach had rank 4 or 3.5 provided that approach $\mathrm{D}$ also had rank $3.5 ;{ }^{\mathrm{e}}$ " $\mathrm{D}$ best" indicates number of times in which approach $\mathrm{D}$ had rank $1 ;$; "D worst" indicates number of times in which this approach had rank 3.5 provided that approach B had rank 1, too. 
Table 4. Summary of rank-ordering of efficiency of stratification approaches A, B, C, and $\mathrm{D}$, for $N=10000$ and various combinations of $\sigma, f, L$.

\begin{tabular}{|c|c|c|c|c|c|c|c|c|c|c|c|}
\hline$\sigma$ & $f$ & $L$ & $\begin{array}{l}\mathrm{A}^{\mathrm{a}} \\
\text { best }\end{array}$ & $\begin{array}{l}\mathrm{A}^{\mathrm{a}} \\
\text { Worst }\end{array}$ & $\begin{array}{l}\mathrm{A}^{\mathrm{b}} \\
\text { failed }\end{array}$ & $\begin{array}{l}\mathrm{B}^{\mathrm{c}} \\
\text { best }\end{array}$ & $\begin{array}{l}\mathrm{B}^{\mathrm{d}} \\
\text { worst }\end{array}$ & $\begin{array}{l}\mathrm{C}^{\mathrm{a}} \\
\text { best }\end{array}$ & $\begin{array}{l}\mathrm{C}^{\mathrm{a}} \\
\text { worst }\end{array}$ & $\begin{array}{l}\mathrm{D}^{\mathrm{e}} \\
\text { best }\end{array}$ & $\begin{array}{l}\mathrm{D}^{\mathrm{f}} \\
\text { worst }\end{array}$ \\
\hline 0.4 & 0.1 & 3 & 0 & 1 & 0 & 0 & 0 & 0 & 0 & 12 & 0 \\
\hline 0.4 & 0.1 & 5 & 15 & 34 & 0 & 1 & 1 & 3 & 2 & 46 & 0 \\
\hline 0.4 & 0.1 & 7 & 18 & 49 & 0 & 0 & 12 & 6 & 10 & 75 & 0 \\
\hline 0.4 & 0.1 & 9 & 10 & 54 & 0 & 0 & 13 & 3 & 17 & 87 & 0 \\
\hline 0.4 & 0.2 & 3 & 0 & 0 & 0 & 0 & 0 & 0 & 0 & 11 & 0 \\
\hline 0.4 & 0.2 & 5 & 6 & 31 & 0 & 0 & 1 & 0 & 1 & 63 & 0 \\
\hline 0.4 & 0.2 & 7 & 9 & 59 & 0 & 0 & 5 & 3 & 12 & 88 & 0 \\
\hline 0.4 & 0.2 & 9 & 8 & 49 & 0 & 0 & 21 & 6 & 13 & 86 & 0 \\
\hline 0.6 & 0.1 & 3 & 0 & 1 & 0 & 0 & 0 & 0 & 0 & 18 & 0 \\
\hline 0.6 & 0.1 & 5 & 7 & 32 & 0 & 0 & 6 & 2 & 1 & 67 & 0 \\
\hline 0.6 & 0.1 & 7 & 12 & 44 & 0 & 0 & 20 & 8 & 21 & 80 & 0 \\
\hline 0.6 & 0.1 & 9 & 9 & 43 & 0 & 0 & 27 & 10 & 18 & 81 & 0 \\
\hline 0.6 & 0.2 & 3 & 0 & 0 & 0 & 0 & 0 & 0 & 0 & 29 & 0 \\
\hline 0.6 & 0.2 & 5 & 11 & 38 & 0 & 1 & 0 & 2 & 4 & 65 & 0 \\
\hline 0.6 & 0.2 & 7 & 15 & 54 & 0 & 0 & 14 & 10 & 12 & 74 & 1 \\
\hline 0.6 & 0.2 & 9 & 0 & 99 & 0 & 0 & 1 & 77 & 0 & 23 & 0 \\
\hline 0.8 & 0.1 & 3 & 0 & 3 & 0 & 0 & 0 & 0 & 0 & 17 & 0 \\
\hline 0.8 & 0.1 & 5 & 13 & 35 & 0 & 0 & 3 & 0 & 3 & 56 & 3 \\
\hline 0.8 & 0.1 & 7 & 12 & 62 & 3 & 0 & 13 & 14 & 11 & 72 & 0 \\
\hline 0.8 & 0.1 & 9 & 26 & 34 & 0 & 0 & 29 & 7 & 27 & 67 & 0 \\
\hline 0.8 & 0.2 & 3 & 0 & 0 & 0 & 0 & 0 & 0 & 0 & 23 & 0 \\
\hline 0.8 & 0.2 & 5 & 8 & 26 & 0 & 0 & 1 & 2 & 1 & 55 & 0 \\
\hline 0.8 & 0.2 & 7 & 4 & 71 & 1 & 0 & 27 & 89 & 1 & 7 & 1 \\
\hline 0.8 & 0.2 & 9 & 0 & 100 & 94 & 0 & 0 & 98 & 0 & 2 & 0 \\
\hline
\end{tabular}

a "A best", "C best", "A worst", and "C worst" indicate number of times in which a particular approach (A or C) had rank 1 (best) or rank 4 (worst); " "A failed" indicates number of time in which numerical problems occurred under approach $\mathrm{A}$, so the solution was not be found; ${ }^{\mathrm{c}}$ "B best" indicates number of times in which this approach had rank 1.5 provided that approach D had rank 1.5, too; "B worst" indicates 
number of times in which this approach had rank 4 or 3.5 provided that approach $\mathrm{D}$ also had rank $3.5 ;{ }^{\mathrm{e}}$ " $\mathrm{D}$ best" indicates number of times in which approach $\mathrm{D}$ had rank $1 ;$; "D worst" indicates number of times in which this approach had rank 3.5 provided that approach B had rank 1, too. 
Table 5. Summary of rank-ordering of efficiency of stratification approaches A, B, C, and $\mathrm{D}$, for $N=15000$ and various combinations of $\sigma, f, L$.

\begin{tabular}{|c|c|c|c|c|c|c|c|c|c|c|c|}
\hline$\sigma$ & $f$ & $L$ & $\begin{array}{l}\mathrm{A}^{\mathrm{a}} \\
\text { best }\end{array}$ & $\begin{array}{l}\mathrm{A}^{\mathrm{a}} \\
\text { worst }\end{array}$ & $\begin{array}{l}\mathrm{A}^{\mathrm{b}} \\
\text { failed }\end{array}$ & $\begin{array}{l}\mathrm{B}^{\mathrm{c}} \\
\text { best }\end{array}$ & $\begin{array}{l}\mathrm{B}^{\mathrm{d}} \\
\text { worst }\end{array}$ & $\begin{array}{l}\mathrm{C}^{\mathrm{a}} \\
\text { best }\end{array}$ & $\begin{array}{l}\mathrm{C}^{\mathrm{a}} \\
\text { worst }\end{array}$ & $\begin{array}{l}\mathrm{D}^{\mathrm{e}} \\
\text { best }\end{array}$ & $\begin{array}{l}\mathrm{D}^{\mathrm{f}} \\
\text { worst }\end{array}$ \\
\hline 0.4 & 0.1 & 3 & 0 & 0 & 0 & 0 & 0 & 0 & 0 & 10 & 0 \\
\hline 0.4 & 0.1 & 5 & 8 & 33 & 0 & 0 & 2 & 0 & 0 & 66 & 1 \\
\hline 0.4 & 0.1 & 7 & 6 & 67 & 0 & 0 & 11 & 3 & 4 & 89 & 0 \\
\hline 0.4 & 0.1 & 9 & 7 & 57 & 0 & 0 & 10 & 5 & 17 & 88 & 0 \\
\hline 0.4 & 0.2 & 3 & 0 & 0 & 0 & 0 & 0 & 0 & 0 & 14 & 0 \\
\hline 0.4 & 0.2 & 5 & 1 & 30 & 0 & 0 & 1 & 0 & 0 & 75 & 0 \\
\hline 0.4 & 0.2 & 7 & 10 & 47 & 0 & 0 & 8 & 10 & 13 & 80 & 0 \\
\hline 0.4 & 0.2 & 9 & 10 & 52 & 0 & 0 & 6 & 3 & 14 & 87 & 0 \\
\hline 0.6 & 0.1 & 3 & 1 & 0 & 0 & 0 & 0 & 0 & 0 & 25 & 0 \\
\hline 0.6 & 0.1 & 5 & 14 & 36 & 0 & 1 & 3 & 1 & 3 & 69 & 1 \\
\hline 0.6 & 0.1 & 7 & 12 & 35 & 0 & 0 & 24 & 7 & 21 & 81 & 0 \\
\hline 0.6 & 0.1 & 9 & 12 & 41 & 0 & 0 & 20 & 1 & 21 & 87 & 0 \\
\hline 0.6 & 0.2 & 3 & 0 & 0 & 0 & 0 & 0 & 0 & 0 & 33 & 0 \\
\hline 0.6 & 0.2 & 5 & 6 & 21 & 0 & 1 & 0 & 0 & 0 & 77 & 0 \\
\hline 0.6 & 0.2 & 7 & 10 & 45 & 0 & 1 & 19 & 21 & 15 & 67 & 0 \\
\hline 0.6 & 0.2 & 9 & 0 & 100 & 0 & 0 & 0 & 86 & 0 & 14 & 0 \\
\hline 0.8 & 0.1 & 3 & 0 & 7 & 0 & 0 & 0 & 0 & 0 & 21 & 0 \\
\hline 0.8 & 0.1 & 5 & 7 & 20 & 0 & 1 & 2 & 3 & 2 & 58 & 0 \\
\hline 0.8 & 0.1 & 7 & 21 & 48 & 3 & 2 & 11 & 7 & 9 & 66 & 0 \\
\hline 0.8 & 0.1 & 9 & 25 & 38 & 2 & 0 & 31 & 13 & 21 & 62 & 0 \\
\hline 0.8 & 0.2 & 3 & 0 & 2 & 0 & 0 & 0 & 0 & 0 & 27 & 0 \\
\hline 0.8 & 0.2 & 5 & 7 & 21 & 0 & 0 & 7 & 5 & 4 & 53 & 1 \\
\hline 0.8 & 0.2 & 7 & 2 & 82 & 0 & 0 & 17 & 93 & 1 & 5 & 0 \\
\hline 0.8 & 0.2 & 9 & 0 & 100 & 97 & 0 & 0 & 98 & 0 & 2 & 0 \\
\hline
\end{tabular}

a "A best", "C best", "A worst", and "C worst" indicate number of times in which a particular approach (A or C) had rank 1 (best) or rank 4 (worst); " "A failed" indicates number of time in which numerical problems occurred under approach $\mathrm{A}$, so the solution was not be found; ${ }^{\mathrm{c}}$ "B best" indicates number of times in which this approach had rank 1.5 provided that approach D had rank 1.5, too; "B worst" indicates 
number of times in which this approach had rank 4 or 3.5 provided that approach $\mathrm{D}$ also had rank $3.5 ;{ }^{\mathrm{e}}$ " $\mathrm{D}$ best" indicates number of times in which approach $\mathrm{D}$ had rank $1 ;$; "D worst" indicates number of times in which this approach had rank 3.5 provided that approach B had rank 1, too. 
Table 6. Mean rank for four approaches compared, under different levels of the population quantities studied.

\begin{tabular}{llllll}
\hline & Items & $\mathrm{A}$ & $\mathrm{B}$ & $\mathrm{C}$ & $\mathrm{D}$ \\
\hline$N=1000$ & 2400 & 2.73 & 2.79 & 2.77 & 1.71 \\
$N=2000$ & 2400 & 2.74 & 2.89 & 2.67 & 1.70 \\
$N=5000$ & 2400 & 2.93 & 2.84 & 2.6 & 1.64 \\
$N=10000$ & 2400 & 2.98 & 2.84 & 2.54 & 1.64 \\
$N=15000$ & 2400 & 2.99 & 2.85 & 2.55 & 1.61 \\
$\sigma=0.4$ & 3200 & 2.81 & 2.81 & 2.77 & 1.61 \\
$\sigma=0.6$ & 3200 & 2.85 & 2.86 & 2.68 & 1.61 \\
$\sigma=0.8$ & 3200 & 2.95 & 2.86 & 2.43 & 1.76 \\
$L=3$ & 2400 & 2.58 & 2.59 & 2.59 & 2.25 \\
$L=5$ & 2400 & 2.92 & 2.81 & 2.78 & 1.49 \\
$L=7$ & 2400 & 2.94 & 2.99 & 2.65 & 1.42 \\
$L=9$ & 2400 & 3.05 & 2.98 & 2.49 & 1.48 \\
$f=0.1$ & 4800 & 2.73 & 2.84 & 2.81 & 1.63 \\
$f=0.2$ & 4800 & 3.02 & 2.85 & 2.45 & 1.69 \\
Totally & 96000 & 2.87 & 2.84 & 2.63 & 1.66 \\
\hline
\end{tabular}

URL: http://mc.manuscriptcentral.com/Issp E-mail: comstat@univmail.cis.mcmaster.ca 
Table 7. Stratification of household income before taxes for 16057 units from the 2001 Survey of Household Spending (SHS) Statistics Canada (source: Baillargeon and Rivest, 2007) for seven strata and sample size $n=1500$. (Sums of stratum sample sizes are different from 1500 due to rounding to integers.)

\begin{tabular}{|c|c|c|c|c|c|c|c|c|c|c|c|c|}
\hline \multirow[t]{2}{*}{ Stratum } & \multicolumn{3}{|c|}{ Approach A } & \multicolumn{3}{|c|}{ Approach B } & \multicolumn{3}{|c|}{ Approach C } & \multicolumn{3}{|c|}{ Approach D } \\
\hline & $k^{1}$ & $N_{h}$ & $n_{h}$ & $k$ & $N_{h}$ & $n_{h}$ & $k$ & $N_{h}$ & $n_{h}$ & $k$ & $N_{h}$ & $n_{h}$ \\
\hline 1 & 0 & 3717 & 200 & 0 & 3717 & 178 & 0 & 2755 & 103 & 0 & 3717 & 202 \\
\hline 2 & 21707.55 & 3351 & 168 & 21862.38 & 2011 & 51 & 17076.72 & 2750 & 87 & 21017.47 & 3351 & 170 \\
\hline 3 & 37177.37 & 3094 & 178 & 30978.86 & 4434 & 311 & 29363.74 & 2358 & 76 & 37365.61 & 2930 & 160 \\
\hline 4 & 55383.14 & 2722 & 195 & 55897.71 & 2548 & 149 & 41727.19 & 3297 & 182 & 54053.91 & 3570 & 363 \\
\hline 5 & 78944.03 & 2079 & 228 & 76158.94 & 1626 & 103 & 62832.64 & 2595 & 183 & 86728.29 & 1886 & 281 \\
\hline 6 & 112557.23 & 1086 & 524 & 99599.61 & 1713 & 701 & 89082.52 & 2294 & 860 & 138399.45 & 595 & 315 \\
\hline 7 & 488693.26 & 8 & 8 & 496513.15 & 8 & 8 & 480472.03 & 8 & 8 & 496177.07 & 8 & 8 \\
\hline $\mathrm{CV}$ & & 00374 & & & .00417 & & & 0.0043 & & & 0.0037 & \\
\hline
\end{tabular}

\footnotetext{
${ }^{1} k$ is a stratum boundary; a particular $h$ th stratum comprises units of which the stratification variable's values are within the interval $\left.<k_{h}, k_{h+1}\right)$
} 